
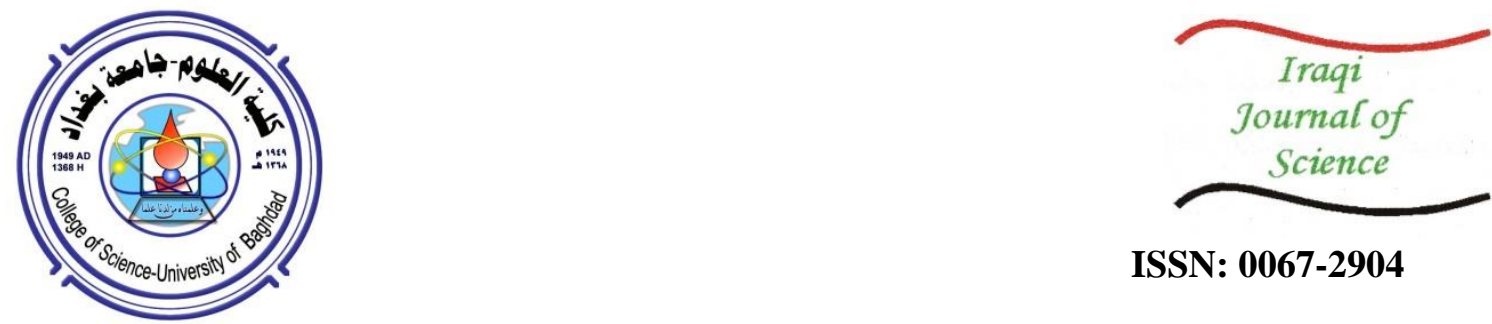

ISSN: 0067-2904

\title{
Studying the Chaotic Dynamics Using Rossler-Chua Systems Combined with A Semiconductor Laser
}

\author{
Raied K. Jamal, Falah H. Ali*, Falah A-H. Mutlak \\ Department of Physics, College of Science, University of Baghdad, Baghdad, Iraq
}

Received: 30/12/2020

Accepted: $22 / 4 / 2021$

\begin{abstract}
In this paper, two different chaotic dynamic systems are coupled using a semiconductor laser to produce a new chaotic system. These two chaotic systems are Rossler and Chua systems. X-dynamic of Rossler system was coupled optically using optical fiber as a carrier of signal with $\mathrm{x}, \mathrm{y}$, and $\mathrm{z}$-dynamics of Chua system. The results were analyzed and the behavior of Chua system was found to be changing in time series which, in turn, changed the attractor. The Chua attractor was converted from double scroll to single scroll. The results obtained from connecting two different systems in chaotic behavior showed a remarkable increase in the bandwidth of Chua system. This increase in bandwidth opens up a wide field for many applications, the most important of which is in the field of secure communications.
\end{abstract}

Keywords: Chaos systems, Rossler circuit, Chua circuit, coupling system, nonlinear dynamics, and secure communication.

\section{دراسة الايناميكية الفوضوية باستخدام نظامين تشوا- روزلار والمقترنة بليزر شبه الموصل}

$$
\begin{aligned}
& \text { رائد كامل جمال ، فلاح حسن علي* ، فلاح عبد الحسن مطلك }
\end{aligned}
$$

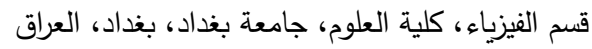

$$
\begin{aligned}
& \text { الخلاصة } \\
& \text { في هذا البحث، تدت عملية ربط نظامين دينامكيين فوضويين مختلفين باستخدام ليزر شبه موصل لإنتاج }
\end{aligned}
$$

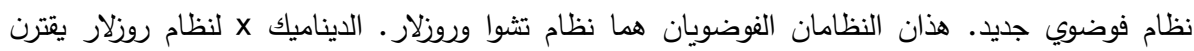

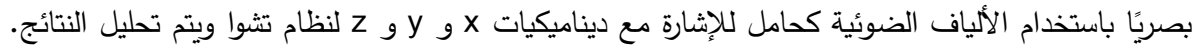

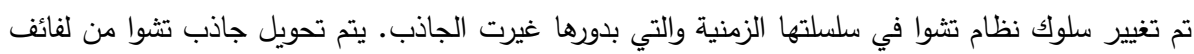

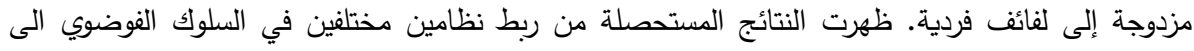

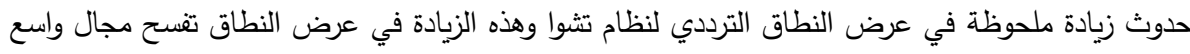

$$
\begin{aligned}
& \text { للتطبيقات كثيرة واهما في مجال الاتصالات الامنة. }
\end{aligned}
$$

\section{Introduction}

Chaos refers to "An irregular oscillation governed by a moderately basic principle" [1]. Here oscillation only refers to a variety of specific amounts. There are numerous sorts of chaotic systems; Lorenz system [2] was utilized in the climate science, the Rossler system in the field of chemical engineering, the Chua system for electrical circuits [3], in addition to the Duffing system in the field of mechanics $[4,5]$. The chaotic systems have important properties; they are dependent on preliminary 
situations and pseudo-randomness, and system parameters. They also have no periodicity and feature huge variety of Fourier spectra [6]. The chaos might be located in a lot of research disciplines, including communication [7-11], electronics, engineering, economics, physics, biology, chemistry, mathematics, steganography [12], and encryption [13]. When engineers use the word chaos, they generally suggest that a predictable dynamics machine can provide unpredictable effects. The simplest way to examine chaos is in electronic circuits. This is because of its simplicity and lower cost and because electronic devices are nicely understood. Chu's and Rossler circuits are examples of chaotic circuits; however, Chua is less complicated than Rossler.

In this paper, two different chaotic dynamic systems (Chua-Rossler) are coupled using a semiconductor laser to produce a new chaotic system, where the influence of $\mathrm{x}$-dynamic of the Rossler's circuit on the behavior of Chua's circuit was studied. There are many previous studies that have used chaos theory to solve and develop many security problems [14-15]. However, the most important of these studies is that being conducted presently, reflecting an attempt to hide important and confidential documents using chaotic technology, which is currently in the process of publication.

\section{Chua's and Rossler's circuits}

Chaotic dynamics may be defined in lots of unique differential equations that can be constructed into an electrical circuit. An instance of an electrical circuit, that is used in this research, is Chua circuit. The differential equations of Chua's circuit are presented below [16]:

$$
\begin{aligned}
& C_{1} \frac{d v_{1}}{d t}=\frac{1}{R}\left(v_{2}-v_{1}\right)-f\left(v_{1}\right) \\
& C_{2} \frac{d v_{2}}{d t}=\frac{1}{R}\left(v_{1}-v_{2}\right)+i_{L} \\
& L \frac{d i_{L}}{d t}=-v_{2} \\
& f\left(v_{1}\right)=G_{b} v_{1}+\frac{1}{2}\left(G_{a}-G_{b}\right)\left(\left|v_{1}+B_{p}\right|-\left|v_{1}-B_{p}\right|\right)
\end{aligned}
$$

In Figure-1, it is shown how the Chua's circuit includes three energy-storing components (2 capacitors $C_{1}$ and as $C_{2}$, and one inductor $L$ ). $C_{1}$ and $C_{2}$ are the parameters of the conductors. $R$ is the changeable resistance and $L$ is the constant value of the coil. $N_{R}$ is the value of the negative resistance. The values $v_{1}$ and $v_{2}$ represent the voltages on $C_{1}$ and $C_{2}$, respectively, while $i_{l}$ represents the current in the inductor $L$, which can measured experimentally, as shown previously [11]. Nevertheless, it can be also theoretically calculated by the differential equation above. The values of $G_{a}, G_{b}$, and $B_{p}$ are defined in Figure-2, whereas table (1) represents all Chua circuit components.

The dimensionless state equations ( $\mathrm{Wu}, 2002)[17]$ are given by:

$$
\begin{aligned}
& \dot{x} \dot{1}=\alpha 1(y 1-x 1-g(x 1)) \\
& \dot{y} 1=x 1-y 1+z 1 \\
& \dot{z 1}=-\beta y 1 \\
& g(x 1)=c 1 x 1+\left(\frac{1}{2}\right)(d-c 1)(|x 1+1|-|x 1-1|)
\end{aligned}
$$

where $x 1, y 1$, and z1 represent $C_{l}, C_{2}$, and $i_{L}$, respectively, $\alpha 1, \beta, c 1$, and $d$ represent $1 / R C_{l}, 1 / L$, $G_{b}$ and $G_{a}$, respectively, and $g(x 1)$ is the nonlinear function (Sometimes called Chua's diode).

The second chaotic circuit that is used in our scheme is Rossler circuit [18]. The electronic circuit of a Rossler is shown in Figure-3. Table-2 presents all Rossler circuit components. The amplifier A4 is switched on when the voltage exceeds $3 \mathrm{~V}$.

Rossler circuit might be specified via the following three-dimensional system related to differential equations (Lynch, 2004) [19]:

$$
\begin{gathered}
\dot{x} 2=-(y 2+z 2) \\
\dot{y} 2=x 2-a 2 y 2 \\
\dot{z} 2=b+x 2 y 2-c 2 z 2
\end{gathered}
$$

The differential equations are defining continuous-time dynamical system which is showing chaotic dynamics related to attractor's fractal properties. It has seven terms, single quadratic non-linearity, and three parameters, in which $a, b, c \in \mathrm{R}$. There are also dimensionless parameters, $x, y$, and $z$ which are three variables that are evolved with continues time. Firstly, the real parameter's values were examined via Otto. Furthermore, the E. Rossler parameters showed values of $a$ and $b=0.2$ and $c=5.7$, 
which implies that the systems is showing chaotic behavior. The initial two equations were linear terms which are creating oscillations in variable $x$ and $y$. The last equation has only a single non-linear term $(x z)$, thus the expected chaotic behavior was considered as a form of the system.

To employ the new chaotic scheme, two chaotic systems were connected, as shown in Figure-4. The Rossler circuit consists of three channels, with any channel can be used to couple with Chua circuit optically via optical fiber, using semiconductor laser as carrier source. It has a wavelength of $850 \mathrm{~nm}$ over a continuous and controlled power range of $1 \mathrm{nW}$ to $2 \mathrm{~mW}$. The description of other laser characteristics includes spectral half bandwidth of $2.5 \mathrm{~nm}$, multimode, maximum continuous output power of $2 \mathrm{~mW}$, beam diameter of $50 \mathrm{~mm}$, beam divergence of $0.2 \mathrm{rad}$, threshold current of laser of $2.5 \mathrm{~mA}$. Then, the two circuits were coupled, i.e. the output variable $\mathrm{x}$ of Rossler circuit is the input variable $\mathrm{x}$ of Chua circuit, as shown in Figure-4.

Single mode optical fiber (SMF) can be considered as an optical fiber developed for carrying light just directly down the fiber. SMF might be carrying more information with a longer distance in comparison to the electrical signals carried in copper coaxial medium, with not much transmission losses, low interferences, as well as elevated bandwidth possibilities; the optical fiber is specified as the almost optimum transmission medium. PD's function is converting the optical signal which comes from Rossler circuit through the optical fiber to an electrical signal at Chua circuit. PD (InGaAs type) has many characteristics, including high-gain, low noise, as well as RF photoreception. The detector's typical bandwidth is $1 \mathrm{GHz}$, current gain (40), bias of $12 \mathrm{~V}$ battery, and peak response of $0.95 \mathrm{~A} / \mathrm{W}$ at $1550 \mathrm{~nm}$.

The Rossler and Chua circuits are disaccorded components. Then, the signal is driven out from the Rossler circuit and drives in the Chua circuit, thus each of the changes in any of the elements related to the first circuit are affecting the second one. The output voltage $x, y$, and $z$ of Chua's circuit are recorded with a digital storage oscilloscope (Tektronix TDS 2024B model). The digital storage oscilloscope is connected with a personal computer (PC) to handle the resulting data.

The dimensionless states' equations of the coupled Chua circuit will be [9]:

$$
\begin{gathered}
\dot{x} 1=\alpha 1(y 1-x 1-g(x 1))-(y 2+z 2) \\
\dot{y} 1=x 1-y 1+z 1 \\
\dot{z} 1=-\beta y 1 \\
g(x 1)=c 1 x 1+\left(\frac{1}{2}\right)(d-c 1)(|x 1+1|-|x 1-1|)
\end{gathered}
$$

\section{Results and discussion}

The time series of the Rossler circuit is shown in Figure-5, which represents the output voltage in $\mathrm{x}$-dynamics, where the output voltage is in the range of +12 to $-9 \mathrm{~V}$, while the time range is 1000 to $5000 \mu \mathrm{s}$. Figure- 6 demonstrates the three state variables $\mathrm{x}, \mathrm{y}$ and $\mathrm{z}$ of Chua's system, where the output voltage values are +7 to $-5.5 \mathrm{~V},+1.27$ to $-1.12 \mathrm{~V}$, and +8.85 to $-8.78 \mathrm{~V}$, respectively.

The second main objective of this experiment is to produce a strange attractor of the Chua circuit. If the attractor exists, the process cannot be random. Since the Chua circuit has three degree of freedom, then its state space is three-dimensional (3D). One way to display a strange attractor is to take a pair of the state variable (e.g. x,y), as shown in Figure-7 that shows double-scroll strange attractor mode, where the variables $\mathrm{x}$ and $\mathrm{y}$ represent the voltages on the capacitors that can be tapped easily. Figures8 and 9 present the strange attractors of the pairs $(\mathrm{x}, \mathrm{z})$ and $(\mathrm{y}, \mathrm{z})$, respectively, that show also doublescroll strange.

When coupling the dynamic variable $\mathrm{x}$ of the Rossler circuit with all the dynamic variables of the Chua circuit (x,y, and $\mathrm{z}$ ) visually, the time series of Chua circuit will change to a new behavior and become as shown in Figure-10, where it is completely different from the first sate. The range values of output voltage are changing as a result of this coupling. Moreover, the attractor of Chua system is showing "double scroll" pattern. This behavior converts to homoclinic chaotic by coupled x-dynamics of Chua circuit with $x, y$, or $\mathrm{z}$ dynamics of Rossler circuit, as shown in Figures-(11, 12,13). Finally, by this scheme, novel chaotic dynamics can be obtained by laser-coupled two different chaotic systems.

Figures- $(14,15)$ show the importance of this work and the benefits of coupling the two different chaotic systems, through the increase in the bandwidth of the Chua system, characterized by a narrow bandwidth which prompts this system to be effective in different applications, the most important of 
which is in secure communications. This fact confirms the results of Fourier transforms obtained before and after coupling. From the results, chaotic systems with attractor of higher dimensions are believed to have important and exciting applications. Figures-(14,15) refer to the spectra of the Fourier transforms of the uncoupling Chua system and the Chua system coupled with the Rossler system, respectively. The results show a wide spectrum in the case of coupling, with the disappearance of the distinctive frequencies evident in the Chua system. In these two figures, it is noticed that the dynamic bandwidth z-coupled became more broad than it is in the case of non-coupling, and this point is very important in the subject of secret communications. Thus, the characteristic frequency of the Chua system has completely disappeared within the wide range formed as a result of the coupling. Thus, the dynamic z-dynamic is more important than the other dynamics due to its discontinuous exponential dicey distribution [20].

\section{Conclusions}

Through the foregoing description, the process of coupling two different chaotic systems in a chaotic behavior can produce a new strong chaotic behavior with a wide bandwidth, especially in the dynamic z2, which leads us to use this new chaotic system in secure communications. The attractor of Chua system is showing a "double scroll" pattern. This behavior is converted to a homoclinic chaotic by the coupled $\mathrm{x}$-dynamics of Chua circuit with $\mathrm{x}, \mathrm{y}$, or $\mathrm{z}$ dynamics of Rossler circuit

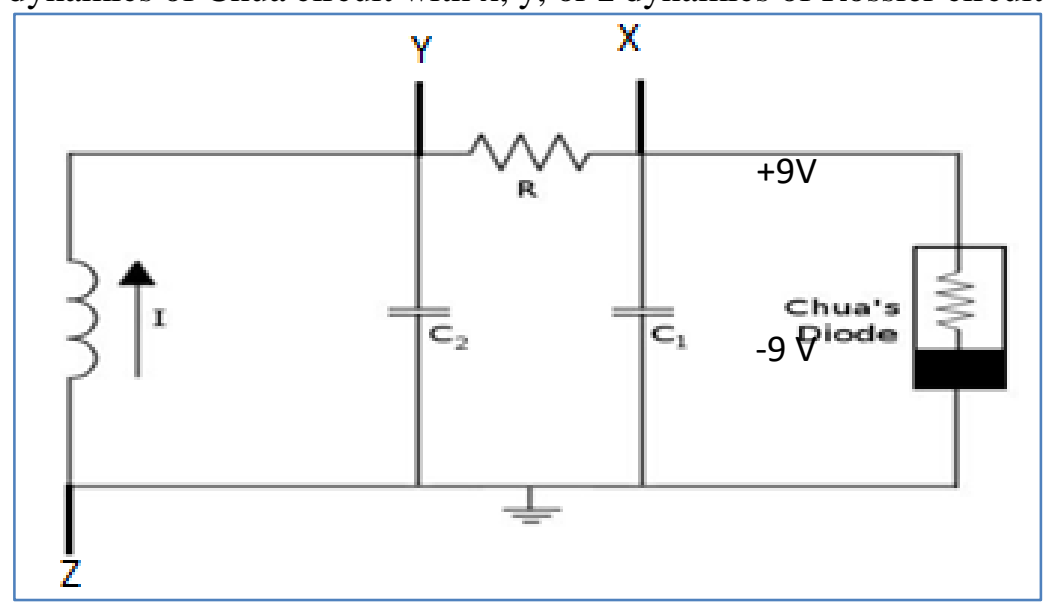

Figure 1- The schematic of Chua's circuit.

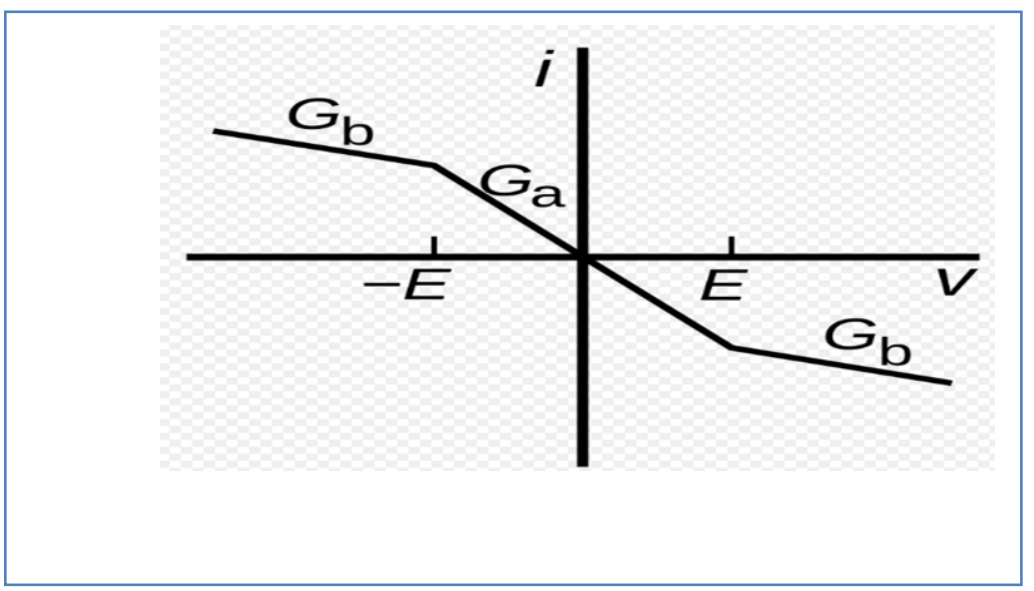

Figure 2- The current-voltage characteristic of the Chua diode.

Table 1- Values of components used in Chua circuit implementation

\begin{tabular}{c|cccccc}
\hline Parameters & $C_{l}$ & $C_{2}$ & $L$ & $R$ & Op-amp. & Power supply \\
\hline Value & $10 \mathrm{nf}$ & $100 \mathrm{nf}$ & $15 \mathrm{mH}$ & $2.5 \mathrm{k} \Omega$ & TLO82 & $\pm 9 \mathrm{~V}$ \\
\hline
\end{tabular}




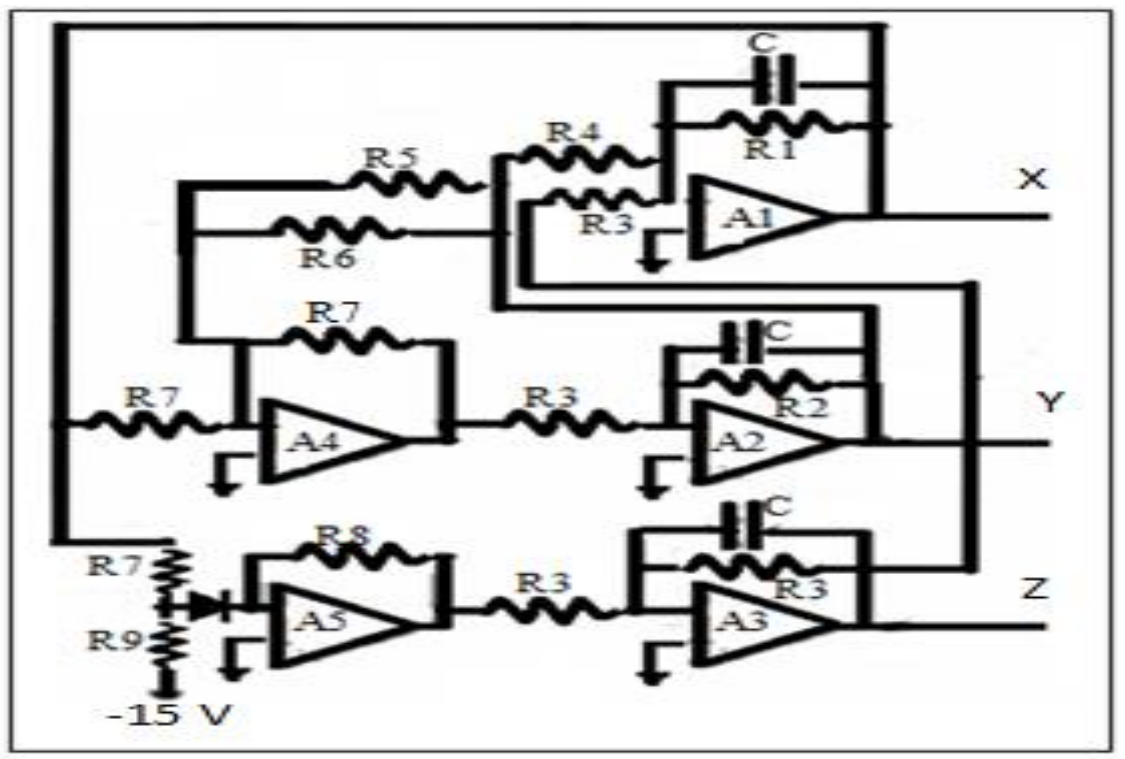

Figure 3- The schematic of Rossler's circuit [11].

Table 2- Values of components used in Rossler circuit implementation

\begin{tabular}{c|ccccccc}
\hline Parameters & $C$ & $R 1$ & $R 2$ & $R 3$ & $R 4$ & $R 5$ & $R 6$ \\
\hline Value & $0.001 \mu$ & $2 M \Omega$ & $5 M \Omega$ & $100 \mathrm{k} \Omega$ & $200 \mathrm{k} \Omega$ & $47 \mathrm{k} \Omega$ & $75 \mathrm{k} \Omega$ \\
\hline Parameters & $R 7$ & $R 8$ & $R 9$ & diode & $\begin{array}{c}\text { Amplifier } \\
(\text { Al-A5) }\end{array}$ & voltage & \\
\hline Value & $10 \mathrm{k} \Omega$ & $150 \mathrm{k} \Omega$ & $68 \mathrm{k} \Omega$ & & $L M 741$ & -15 & \\
\hline
\end{tabular}

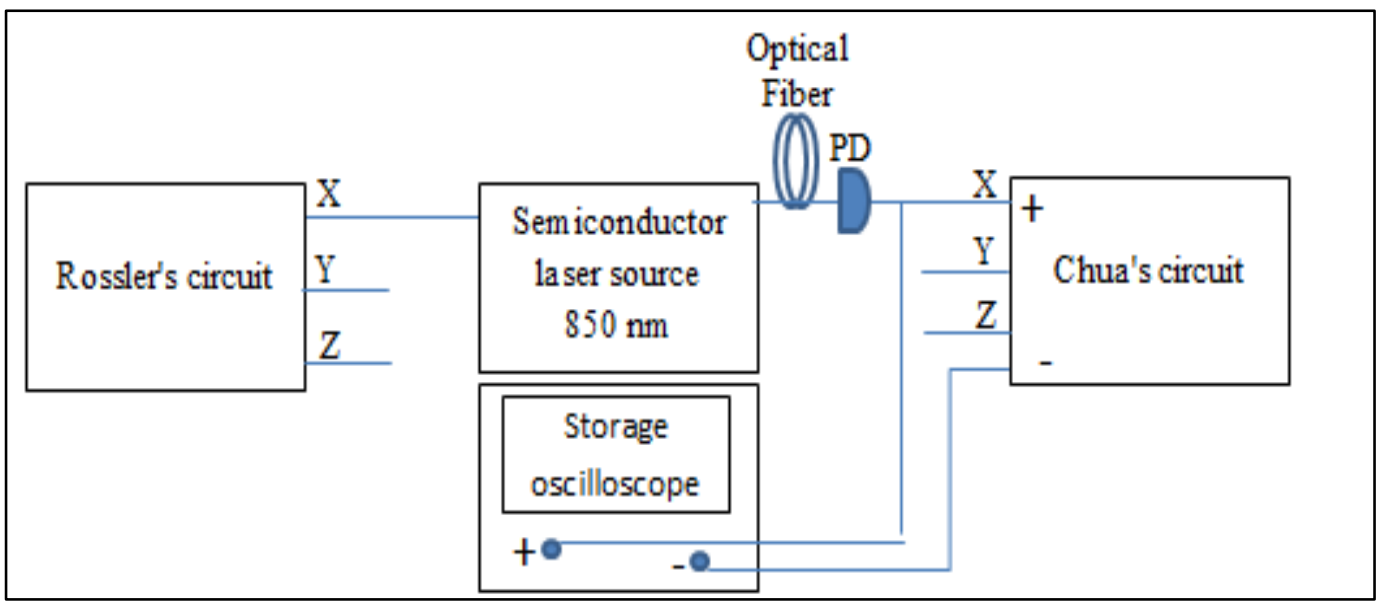

Figure 4- New chaotic dynamic scheme.

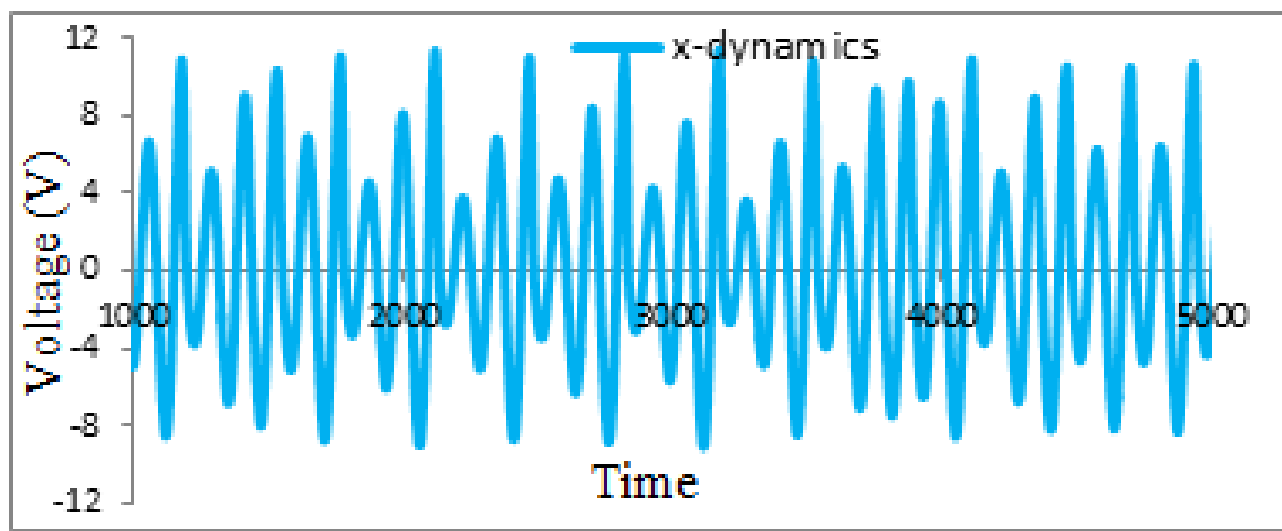

Figure 5- Time series of x-dynamics of Rossler system. 


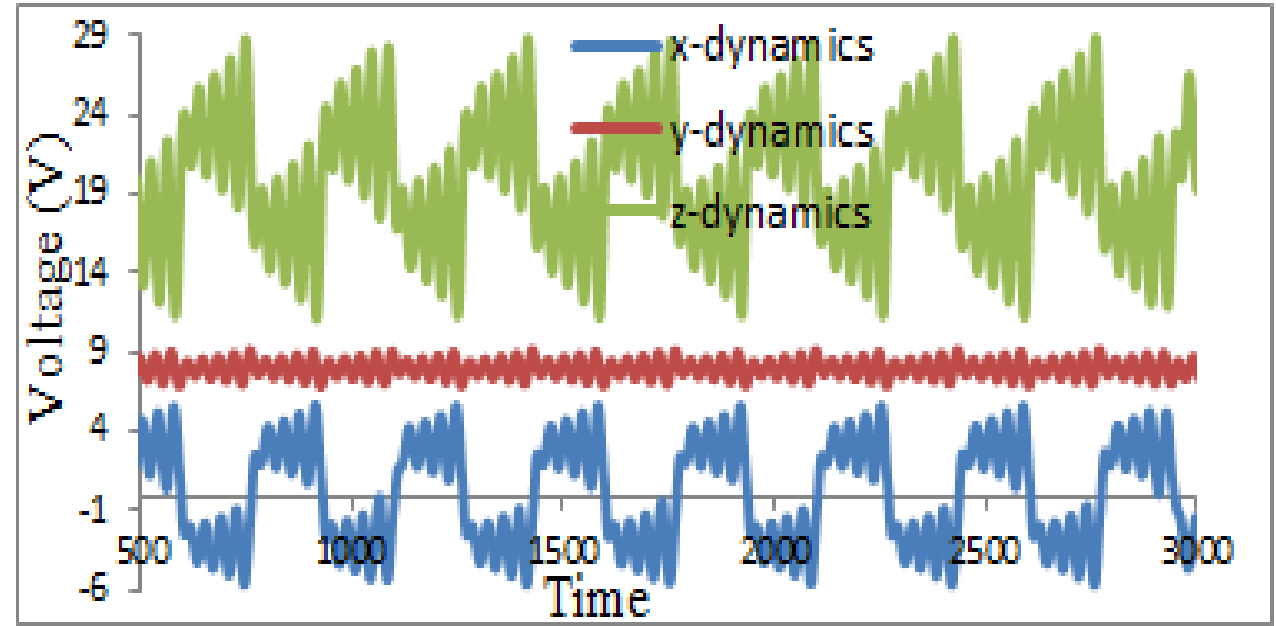

Figure 6- Time series of x, y, and z-dynamics of Chua system.

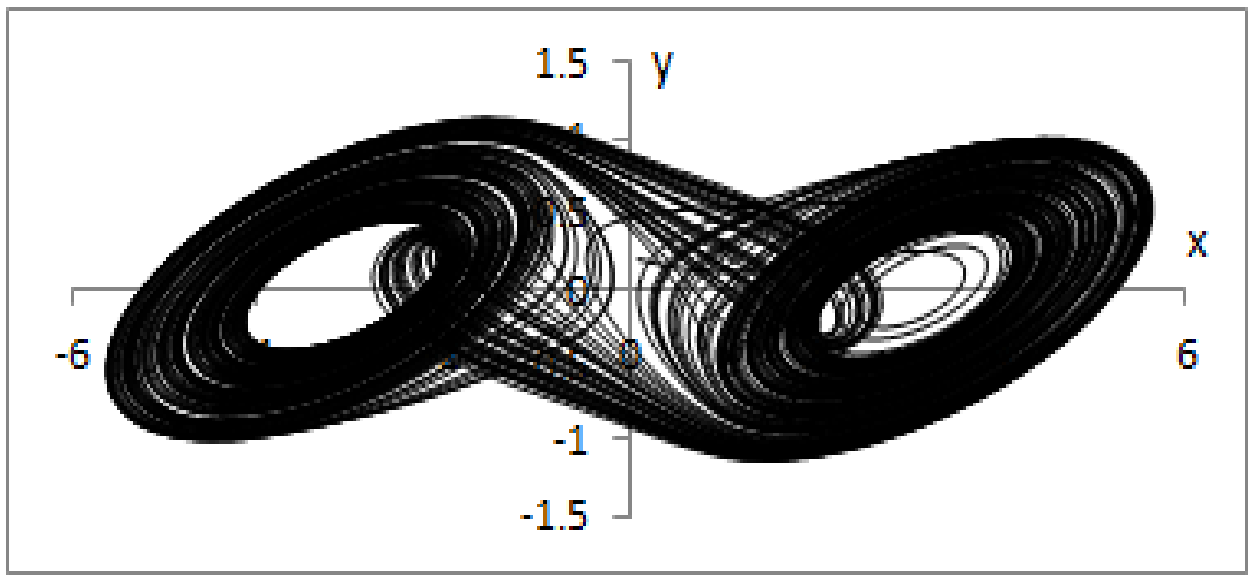

Figure 7- Strange attractor in(x-y) dynamics of Chua system.

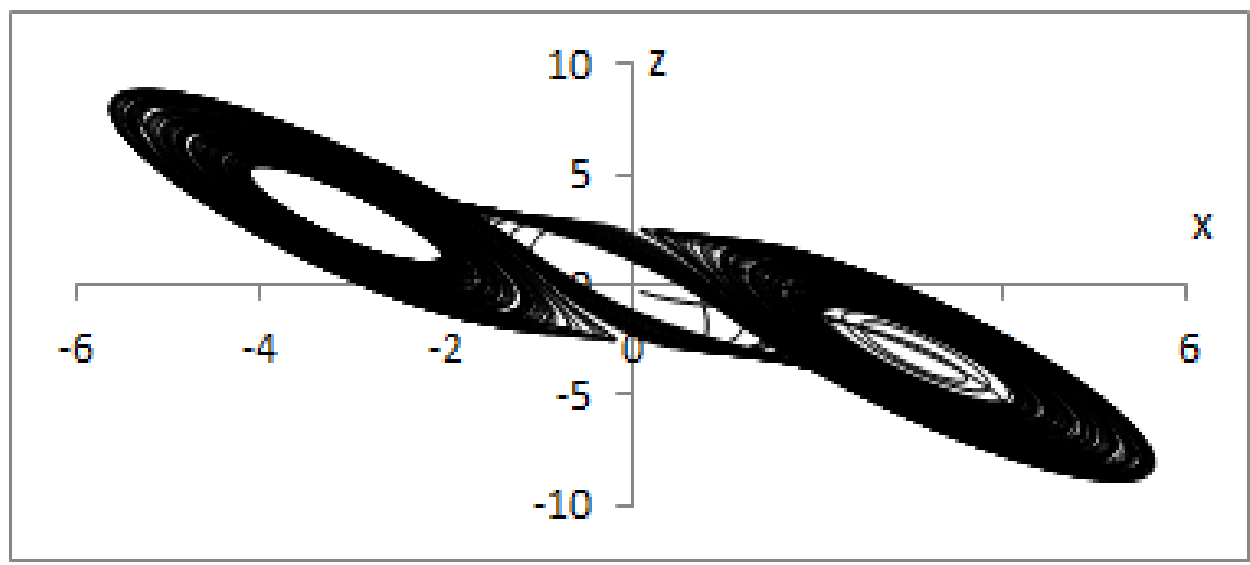

Figure 8- Strange attractor in(x-z) dynamics of Chua system. 


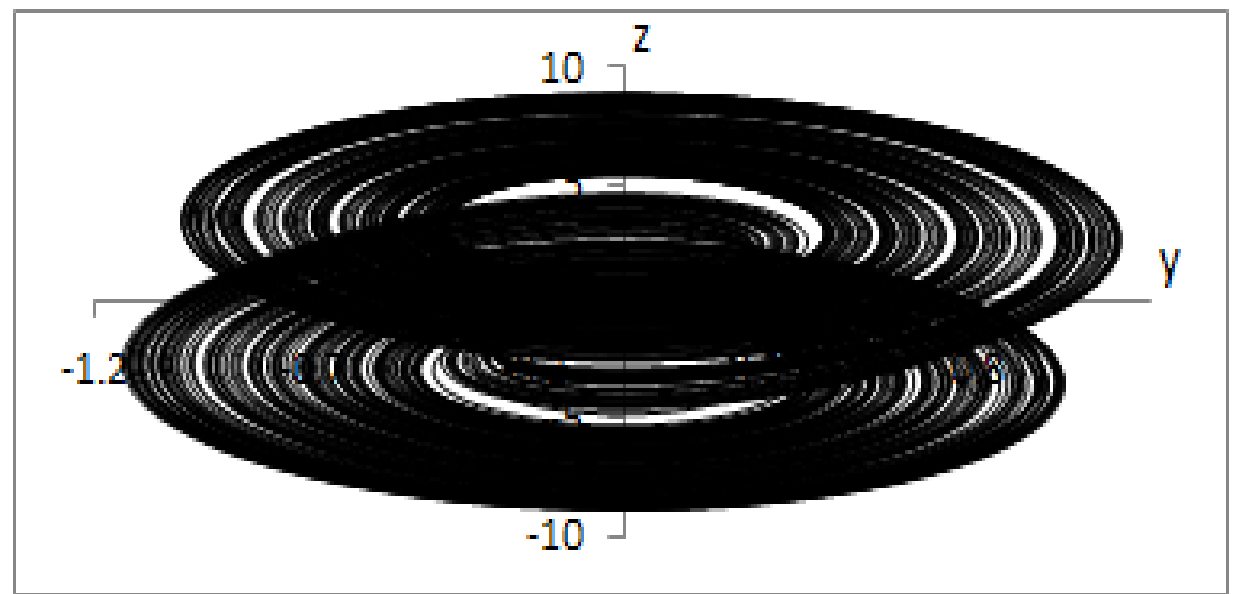

Figure 9- Strange attractor in (y-z) dynamics of Chua system.

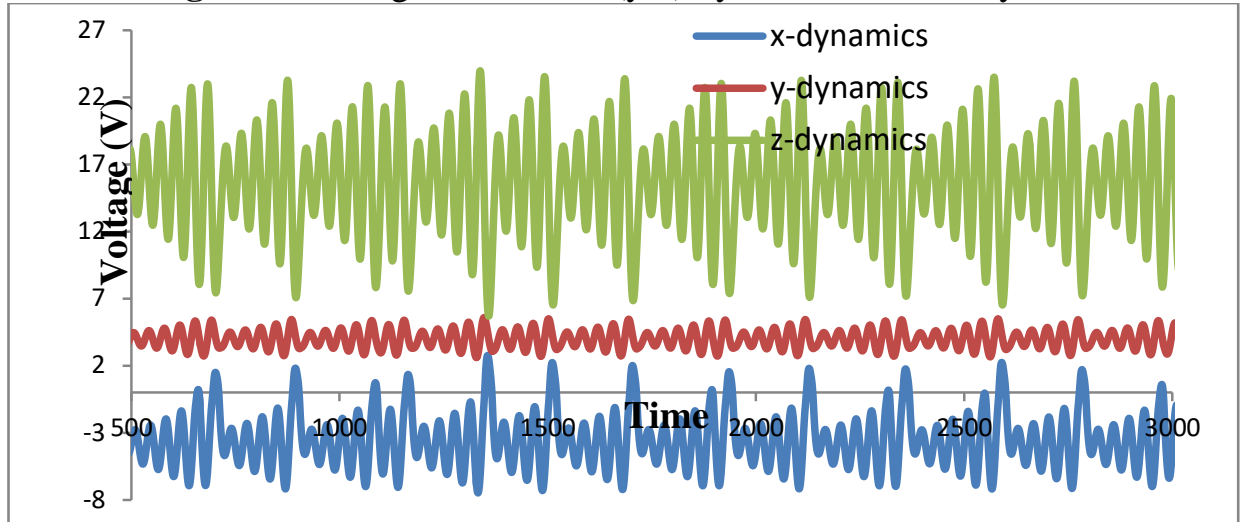

Figure 10- Time series in $\mathrm{x}, \mathrm{y}$, and $\mathrm{z}$-dynamics of Chua system with new scheme.

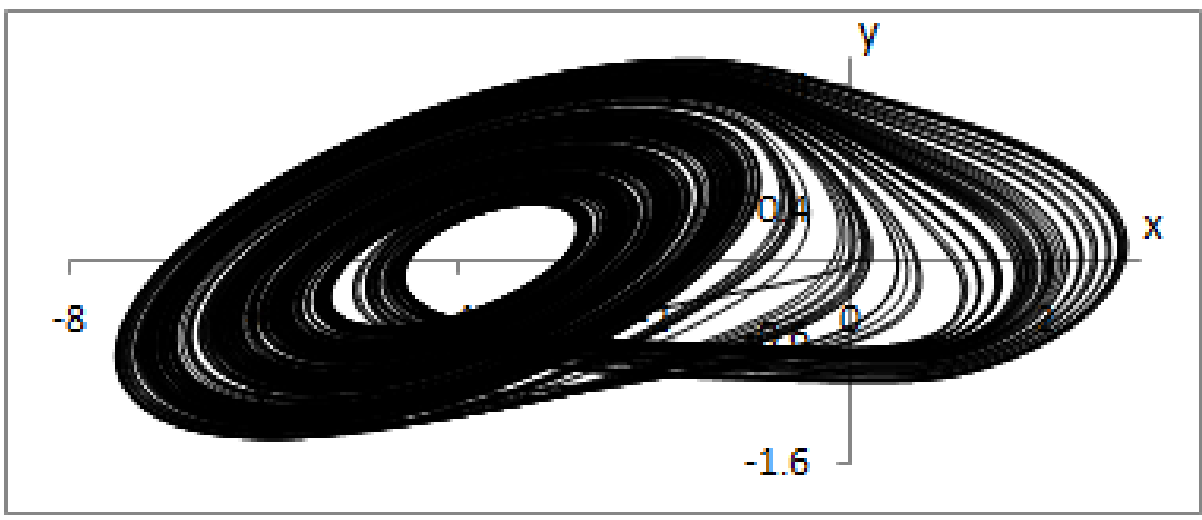

Figure 11- Strange attractor in (x-y) dynamics of Chua system with new scheme.

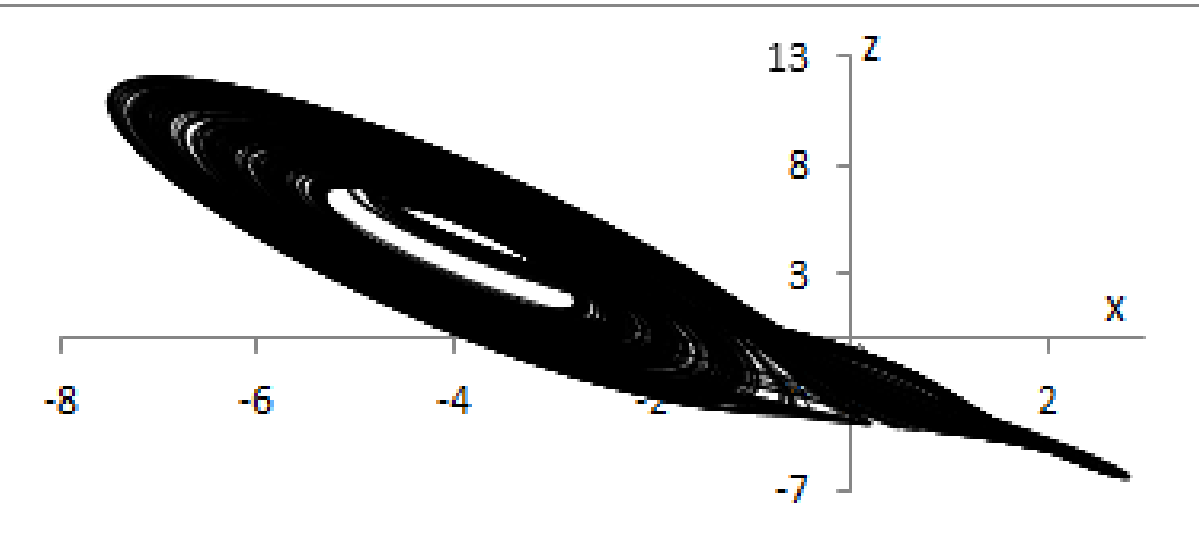

Figure 12- Strange attractor in $(x-z)$ dynamics of Chua system with new scheme. 


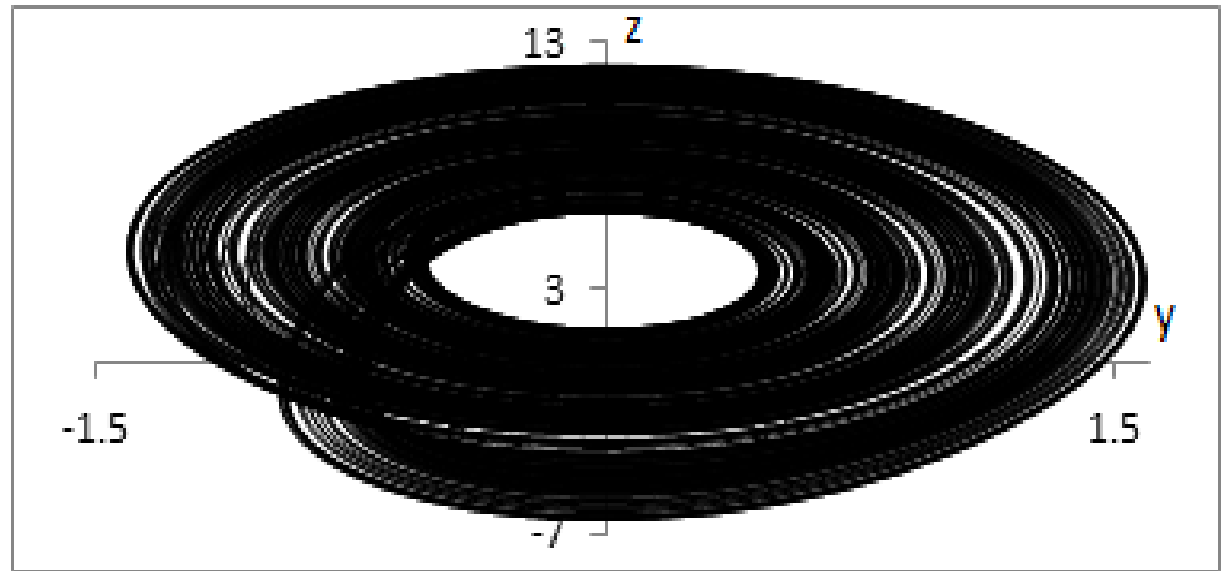

Figure 13- Strange attractor in(y-z) dynamics of Chua system with new scheme.

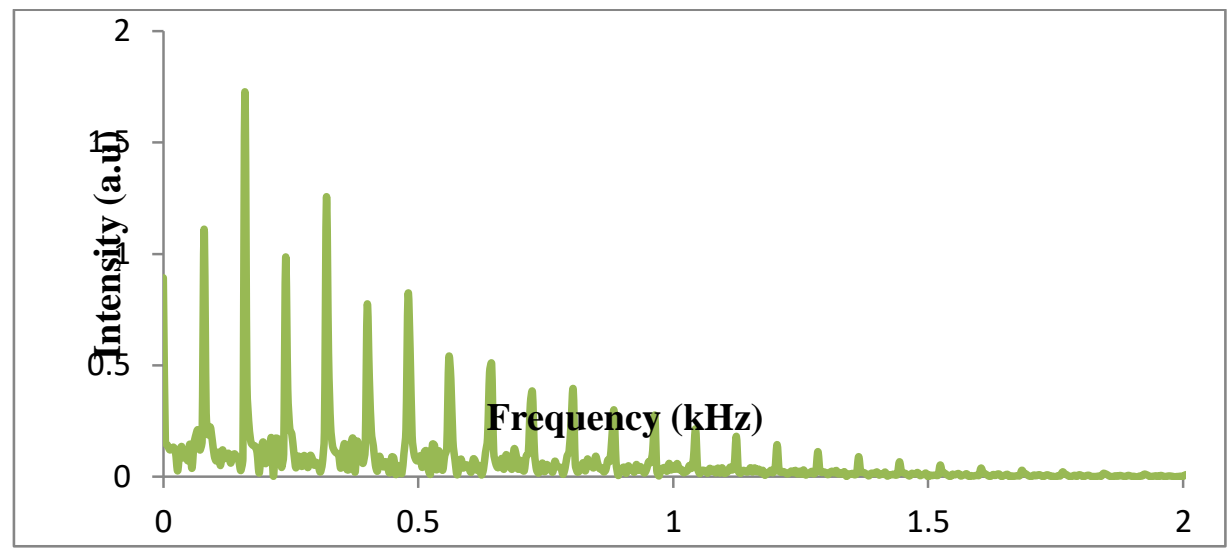

Figure 14- FFT spectrum of z-dynamics of Chua system.

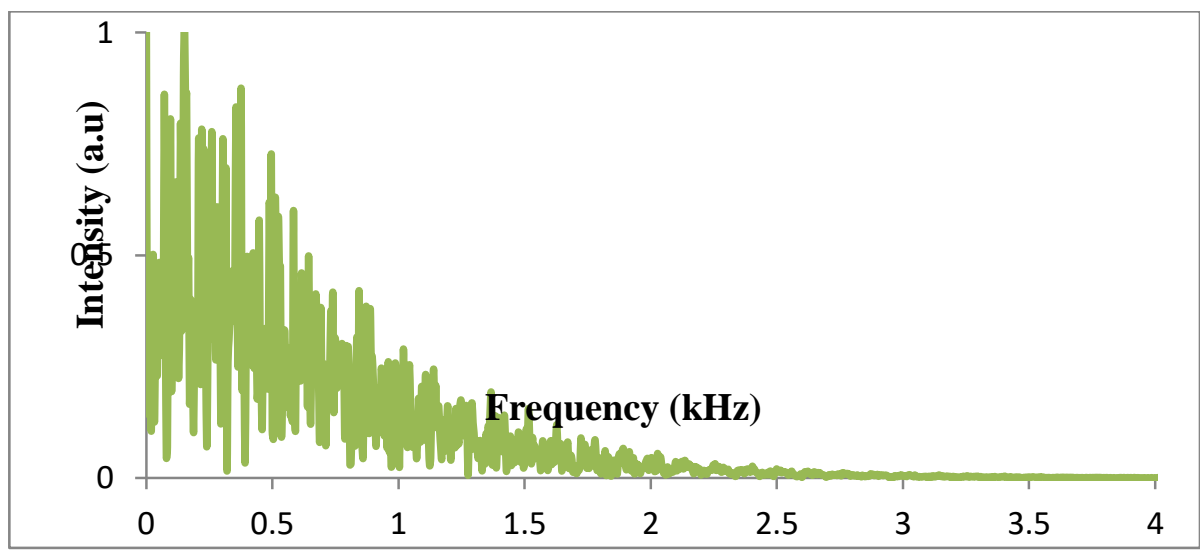

Figure 15- FFT spectrum of z-dynamics of Chua system with new scheme.

\section{References}

1. T. Y. Li and J. A. Yorke 1975. "Period Three Implies Chaos", American Mathematical Monthly, 82(1975): 85-92.

2. E. N. Lorenz. 1963. "Deterministic nonperiodic flow", Journal of the Atmospheric Sciences, 20 (1963):130-141.

3. L. O. Chua and G. N. Lin. 1990. "Canonical realization of Chua's circuit family", IEEE transaction on circuit and systems, 37(1990): 885-902.

4. Trott, M. 2005."The Mathematica Guidebooks Additional Material: Wigner Function of a Duffing Oscillator. https://mathworld.wolfram.com/DuffingDifferentialEquation.html. 
5. A. I. Lerescu, N. Constandache, S. Oancea, and I. Grosu. 2004. "Collection of master-slave synchronized chaotic system", Chaos solitons and fractals, 22(2004): 599-604.

6. Hiroyuki Nagashima and Yoshikazu Baba. 1992. "Introduction to Chaos", Published by Institute of Physics Publishing, wholly owned by The Institute of Physics, LondonInstitute of Physics Publishing, Dirac House, Temple Back. Bristol BSI 6BE, UK.

7. R. K. Jamal and D. A. Kafi. 2016. "Secure communications by chaotic carrier signal using Lorenz model", Iraqi Journal of Physics, 14(2016): 51-63.

8. Dina Ahmed Kafi, Raied Kamel Jamal, K. A. Al- Naimee. 2016. "Lorenz model and chaos masking /addition technique", Iraqi Journal of Physics, 14(2016): 51-60.

9. R. K. Jamal and A. H. Mohamed. 2017. "Secure communication by using Chua's model", International Journal of ChemTech Research, 10(2017): 739-749.

10. R. K. Jamal and D. A. Kafi. 2019. "Secure Communication Coupled Laser Based on Chaotic Rössler Circuits", Nonlinear Optics, Quantum Optics, 51(2019): 79-91.

11. Raied K. Jamal, and Dina A. Kafi. 2019. "Secure Communication Coupled semiconductor Laser Based on Rössler Chaotic Circuits", IOP Conf. Series: Materials Science and Engineering, 571(2019): 1-9.

12. R. Banupriya, J. Deepa, and S. Suganthi. 2019. "Video steganography using LSB algorithm for security application", Int. J. Mech. Eng. Technol., 10(2019): 203-211.

13. Z. Hua, Y. Zhou, and H. Huang. 2019."Cosine-transform-based chaotic system for image encryption", Inf. Sci., 480(2019): 403-419.

14. Zainab Ali Kamal, Alaa F. Kadhim, dralaa. 2018."Generating dynamic S-BOX based on particle swarm optimization and chaos theory for AES", Iraqi journal of science, 59(2018): 1733-1745.

15. Abeer Tariq Maolood, Ala'a Talib. 2018. "Khudhair towards generating robust key based on neural networks and chaos theory", Iraqi journal of science, 59(2018): 1518-1530.

16. V. D. Broek, and T. H. A. 2004." Chua's circuit : syncronization", TechnischeUniversiteit Eindhoven, 2004. https://www.slideshare.net/balzasbravas/chuas-circuit.

17. Chai Wah Wu. 2002. "Synchronization in coupled chaotic circuits and systems", World Scientific series A, 41(2002): 157-159.

18. O. E. Rossler. 1976. "An equation for continuous chaos", Phys. Lett., 57(1976): 397-398.

19. Stephen Lynch. 2004. "Dynamical systems with application using Matlab", Birkhauser, 2004.

20. Salam K. Mousa, and Raied K. Jamal. 2021." Realization of a novel chaotic system using coupling dual chaotic system", Optical and Quantum Electronics, 53(2021):1-9. 